Avrupa Bilim ve Teknoloji Dergisi

Sayı 18, S. 338-346, Mart-Nisan 2020

(C) Telif hakkı EJOSAT'a aittir

Araștırma Makalesi
European Journal of Science and Technology

No. 18, pp. 338-346, March-April 2020

Copyright (C) 2020 EJOSAT

$\underline{\text { Research Article }}$

\title{
Uçak Sistemlerinin SCADA İle Modellenmesi
}

\author{
Furkan İşbilen $^{1}$, Mehmet Konar ${ }^{2 *}$ \\ ${ }^{1}$ Erciyes Üniversitesi, Fen Bilimleri Enstitüsü, Sivil Havacılık Anabilim Dalı, Yüksek Lisans Öğrencisi, Kayseri, Türkey \\ ${ }^{2}$ Erciyes Üniversitesi, Havacılık ve Uzay Bilimleri Fakültesi, Uçak Elektrik-Elektronik Bölümü, Kayseri, Türkiye (ORCID: 0000-0002-9317-1196)
}

(İlk Geliş Tarihi 7 Ocak 2020 ve Kabul Tarihi 29 Şubat 2020)

(DOI: $10.31590 /$ ejosat.686048)

ATIF/REFERENCE: İşbilen, F. \& Konar, M. (2020). Uçak Sistemlerinin SCADA İle Modellenmesi. Avrupa Bilim ve Teknoloji Dergisi, (18), 338-346.

\section{Öz}

Teknolojinin gelişmesiyle birlikte, meydana gelen uçak kazalarının temel sebepleri arasında, sistemsel faktörler yerine daha çok insan kaynaklı faktörler yer almaktadır. İnsan kaynaklı faktörler, uçuş güvenliğini ciddi bir şekilde etkilemektedir. Uçuş güvenliği sadece uçuş boyunca değil, aynı zamanda uçuş öncesinde de dikkate alınmalıdır.

Bu çalışmada, hava araçlarının harici güç ünitesinin ve Stall uyarı sistemlerinin, Supervisory Control and Data Acquisition (SCADA) ile tasarımı yapılmıştır. Uçakların yerde bakım ve zorunlu hizmetleri yerine getirme süreçleri boyunca, kullanılan harici güç ünitesinin aktif ve deaktif edilmesi esnasında, gerekli prosedürlerin yerine getirilmesinin kontrolünün SCADA ile sağlanması amaçlanmıştır. Uçuş boyunca, uçuş güvenliğini önemli derecede belirleyen sistemlerden biri olan Stall uyarı sistemi de SCADA ile tasarlanmıştır. Böylece, uçuş güvenliğini etkileyen iki sistemin tasarım modellemesi yapılarak, meydana gelebilecek kazaları en aza indirmek için alternatif bir yaklaşım sunulmuştur. Elde edilen sonuçlar, SCADA yazılımının, kullanıcılar açısından, erişim kolaylığı ve görsel ikaz yöntemi sayesinde, havacılıkta insana bağlı meydana gelen iş kazalarına karşı iş güvenliğini arttıracak alternatif bir çözüm yöntemi olduğunu göstermiştir.

Anahtar Kelimeler: Stall Uyarı Sistemi, SCADA, Uçaklar, Harici Güç Ünitesi.

\section{Modeling Of Aircraft Systems With SCADA}

\begin{abstract}
With the development of technology, among the main causes of plane crashes are more human-induced factors than the system factor. Man-made factors seriously affect flight safety. Flight safety should be considered not only throughout the flight, but also before the flight.

In this study, the external power unit and Stall warning systems of aircrafts were designed with Supervisory Control and Data Acquisition (SCADA). It is aimed to provide control with SCADA of the fulfillment of the necessary procedures during the active and deactivation of the external power unit used during the aircraft maintenance and obligatory services. During the flight, the Stall warning system, which is one of the systems that significantly determines flight safety, was also designed with SCADA. Thus, an alternative approach is presented to minimize accidents that may occur by designing two systems that affect flight safety. The obtained results showed that SCADA software is an alternative solution method that will increase occupational safety against humanrelated work accidents due to the ease of access and visual warning method by users.
\end{abstract}

Keywords: Stall warning system, SCADA, Aircrafts, External Power Unit.

\footnotetext{
* Sorumlu Yazar: Erciyes Üniversitesi, Havacılık ve Uzay Bilimleri Fakültesi, Uçak Elektrik-Elektronik Bölümü, Kayseri, Türkiye, ORCID: 00000002-9317-1196, mkonar@erciyes.edu.tr
} 


\section{Giriş}

Teknolojinin gelişmesiyle hava taşıtları da gelişmiş ve insanların ulaşım sürelerini kısaltmıştır. Hava taşımacılığı için, süreyle birlikte uçuş güvenliği de dikkat edilmesi gereken en önemli faktörler arasındadır. Uçuşun her safhasının güvenli şekilde tamamlanması için, dikkat edilmesi gereken faktörlerin her birinin en üst düzeyde gerçekleştirilmesi gerekmektedir. Uçuş güvenliği için uçuş safhalarıyla birlikte bakım safhasında iyi bir şekilde gerçekleştirilmelidir. Bakım esnasında da ilgili prosedürlerin güvenli bir şekilde uygulanması son derece önemlidir. Bakım ve uçuş esnasında, hava aracı sistemlerinin durumlarının izlenmesi gerekmektedir. Bu sistemlerin alternatif bir yöntemle izlenmesi, bakım ve uçuş güvenliği için büyük katkı sağlayacaktır [1-3].

Yaşanan uçak kazalarında, temel sebepler ya sistemsel hatalara ya da insan kaynaklı hatalara dayanmaktadır. Bununla birlikte, teknolojinin gelişmesi uçakta bulunan sistemlerin daha kolay bir şekilde hacklenmesine (Hijack) firsat tanımıştır. Dolayısıyla, uçuş güvenliğini sağlayan bu sistemlerin, kötü amaçlı kişilerin müdahalelerine karşı korunması ve bu sistemler için gereken önlemlerin alınması gerekmektedir. Bahsedilen bu problemin üstesinden gelmek için, alternatif çözümlerin üretilmesi gerekliliği açığa çıkmıştır.

Enerji kullanımı her alanda olduğu gibi havacılık sektöründe de önemli bir konudur. Havacılık alanında yaşanan gelişmeler ile uçak sistemleri de gelişmiştir. Uçaklarda yer alan bu gelişmiş uçak sistemleri için enerji ihtiyacı, uçuş esnasında motor jeneratörleri, yedek güç ünitesi (Auxiliary Power Unit, APU), bataryalar veya Ram Air Turbin (RAT) gibi cihazlar ile sağlanmaktadır. Uçaklar yerde iken bu enerji ihtiyacı Harici Güç Kaynağı (External Power Unit, EPU) tarafından sağlanmaktadır [4]. EPU, motor çalıştırılması, ışıklandırma, zorunlu hizmetlerin yerine getirilmesi gibi bakım sürecinde kullanılan bir ünitedir. Dolayısıyla, uçaklarda EPU'ların aktif ve deaktif edilmesi esnasında uyulması gereken prosedürler ve emniyet yöntemleri mevcuttur. Bu prosedürlere ve emniyet yöntemlerine dikkatlice uyulmadığı takdirde istenmeyen iş kazaları oluşabilmektedir. Örneğin, hidrolik pompaları kapatılmadan (off) yapılmadan EPU ile uçağa enerji verildiği takdirde, uçuş kontrol yüzeylerine hidrolik basınç gönderilir ve kontrol yüzeyi hareket eder. Bu durumda kontrol yüzeyi çevresinde bulunan personelin zarar görmesine neden olabilir. Böyle kazaların yaşanmasını ve istenmeyen durumların oluşmasını önlemek için gerekli prosedürlerin ve emniyet yöntemlerinin dikkatlice uygulanması gerekmektedir [5].

SCADA uzaktan otomasyon sistemlerinin, kullanıcıya görsel olarak (monitoring) bilgi ve kontrol hakkı sunmasından dolayı birçok sektörde kullanılmaktadır. Havacılık sektöründe, havaalanlarının ışıklandırma sistemlerinde sıklıkla tercih edilmektedir [6-8]. Havacılık sektöründe, özellikle havaalanı 1şıklandırma sistemlerinde enerji tasarrufu ve minimum işletme maliyeti hedefleri için kullanılmaktadır.

Bu çalışmada, hava araçlarına ait EPU ve Stall Uyarı Sisteminin (SUS) SCADA ile tasarımı ele alınmıştır. Bu amaçla, EPU'nun aktif ve deaktif edilmesi esnasında gerekli prosedürlerin yerine getirilmesinin kontrolünün ve uçuş güvenliğini önemli derecede belirleyen sistemlerden biri olan SUS'un, SCADA ile tasarımının modellemesi yapılmıştır. Böylece, uçuş güvenliğini etkileyen iki sistemin tasarım modellemesi yapılarak, meydana gelebilecek kazaları en aza indirmek için alternatif bir yaklaşım sunulması amaçlanmıştır. Bu çalışmaya ait ön çalışmalar daha önce (II. Uluslararası Multidisipliner Çalışmaları Kongresinde) sunulmuştur. Bu çalışmada, bahsedilen ön çalışmaların genişletilmiş hali ele alınmıştır [1,2].

Çalışmanın ikinci bölümünde modellenen hava aracı sistemlerinden, üçüncü bölümünde SCADA'dan bahsedilmiştir. Dördüncü bölümde hava aracı sistemlerinin SCADA ile tasarımının uygulamaları verilmiştir. Son bölümde ise sonuçlar sunulmuştur.

\section{Modellenen Hava Aracı Sistemleri}

Bu bölümde, uçuş ve bakım güvenliğini önemli derecede etkileyen ve SCADA ile tasarımı gerçekleştirilen Stall uyarı sistemi ve harici güç sistemleri kısaca ele alınmıştır.

\subsection{Stall Uyarı Sistemi}

Hava araçları yanlamasına, uzunlamasına ve dikey eksen olmak üzere üç kumanda ekseninde dengede kalarak uçuşunu gerçekleştirir. Hava araçları, eksenleri etrafında herhangi bir değişim olmadığı müddetçe havada güvenli bir şekilde uçuşlarını sürdürürler. Uçuşa bağlı olarak yakıt tüketimi ve çevresel hava şartları hava araçlarının yatay doğrultuda dengesini kaybetmesine neden olmaktadır. Yatay doğrultuda yaşanan dengeyi tekrar kazanmak için veya uçağın havada güvenli bir şekilde seferine devam etmesi için hava aracı üzerindeki hareketli yüzeylerin konumu değiştirilerek yeni şartlara bağlı olarak hava aracı dengesi sağlanır [3].

Hava aracının bozulan dengesi, hava araçlarında bulunan yardımcı ekipmanlar yardımıyla veya pilot kontrolüyle düzeltilerek, hava aracının güvenli bir şekilde seferine devam etmesi sağlanır. Uçaklar, değişen çevresel şartlarını algılayan birçok sensöre sahiptir. Sensörler sayesinde elde edilen hassas değişimler, sinyale dönüştürülür. Bu sinyaller, göstergelere iletilerek uçuş mürettebatının bilgilendirilmesinin yanı sıra uçuş güvenliğini sağlayan yardımcı elemanlara da bilgi gönderir [4,9].

İnsan beyninin, hızla değişen çevresel şartları hesaplaması ve buna göre komut üretme yeteneği yetersiz kaldığı için, gelişen teknoloji ile uçağın hassas değişimlere karşı duyarlı olması ve hareketli yüzeylere komut verilmesi günümüzde bilgisayarlar yardımı ile sağlanmaktadır. Güvenli bir uçuşun gerçekleşmesini engelleyen çeşitli faktörler vardır. Bu faktörlerin başında stall faktörü gelmektedir. Stall, uçağın uçmasını sağlayan temel kuvvetlerden en az birinin dengeleyici kuvvetini kaybederek uçağın hava akışına karşı dengesini kaybetmesidir. 
SUS'un amacı, uçak stalla girmeden önce pilotu uyarmaktır. Uçağın hücum açısı stall için uygun değere ulaştığında, sistem göstergelerinin yanması ve ilgili uyarı kornasının aynı anda etkileşim haline gelmesiyle, uçuş mürettebatı uyarılır. Stall uyarı sistemlerinin birçok çeşidi vardır. Fakat hepsinin amacı çok geç olmadan pilotları stalla karşı uyarmaktır.

Eski uçaklardaki stall uyarı sistemleri sadece hücum açısını etkileyen sarsıcı (shaker), destekleyici (pusher) ve aktüatör (actuation) elemanlarından oluşmaktaydı. İlerleyen yıllar içinde, kontrol valfinin zamana bağlı açısını kontrol eden bir ekipman eklenerek, kanat hücum açısı daha verimli bir şekilde kontrolü sağlanmıştır. Bu durum, düşük stall hızlarında tatmin edici sonuçlar alınmasını sağlamıştır. Günümüz modern uçaklarında geliştirilen modifikasyonlarla, SUS'un hassasiyeti arttırılmış ve hata oranı azaltılmıştır [6].

Hava araçlarında, SUS'un çalışması, alıcı, kontrol ve harekete geçirme birimleri olmak üzere üç temel birimin ortak çalışması prensibine dayanmaktadır. Alıcı birim, uçuş sırasında, uçağın hareketli yüzeylerinde bulunan sensörler yardımıyla kanat üzerindeki hava akışını algılayarak, analog bir çıktı (output) üretir. Sensörler tarafindan algılanan çıktılar, hava veri bilgi sistemi aracıllğıyla göstergelere ve diğer interfacing sistemlere iletilir. Hava veri bilgi sistemi, bir adet toplam hava sıcaklığı (Total air temperature, TAT) probu, iki adet hava veri bilgisayarı (Air data computer, ADC) ve iki adet hücum açısı (AoA) sensörlerinden oluşur. Ayrıca, iki adet harici test butonuna sahiptir [10-13].

Çeşitli bilgisayarlardan oluşan kontrol birimi, alıcı birimde oluşturulan çıktıları değerlendirerek, harekete geçirme birimine girdi (input) olarak bilgi gönderir. Sensörlerden gelen analog sinyaller düşük seviyede olduğu için bu sinyallerin istenilen seviyeye getirilmesi için yükselteç veya röle gibi ekipmanlar kullanılır. Merkezi olarak ADC'ler tarafından yönetilen kontrol birimi, pnömatik ve elektriksel çıktıları, girdi olarak kullanır. Dinamik ve statik hava basınc bilgisi pito-statik sistem ile, toplam hava sıcaklığı bilgisi ise TAT propları ile ADC'lere gönderilir. Son olarak SUS'un çalışma bilgisini barındıran hücum açısı bilgisi de ADC'ye resolver voltages'lar tarafından gönderilir. Sonuncu birim olan harekete geçirme birimi, farklı tipte yardımcı motor elemanlarından meydana gelir. Hava aracı üzerinde oluşan düzensiz hava akışını dengeleyecek hareketli yüzeylerin ayarlanması yardımcı motorlar ile sağlanmaktadır. Kanat üzerinde bulunan kanatçıklar, servo motorların yer aldığı sistemde yapılacak harekete bağlı olarak uygun yön ve şiddette kuvvetler uygulayarak, kanat üzerindeki hava akışını düzene sokmayı amaçlar.

\subsection{Harici Güç Ünitesi}

Hava aracı bakımları hangarda ya da apronda yapılmaktadır. Bu bakımlar esnasında gerekli sistemleri beslemek için hava aracının enerjilenmesi gerekmektedir. Hava araçları bakım esnasında APU ve EPU ile enerjilendirilebilmektedir [4]. EPU, hava araçlarının park süresi içerisinde, motor çalıştırılması, ışıklandırma, zorunlu hizmetlerin yerine getirilmesi ve elektrik sisteminin testi için gerekli olan elektrik enerjisini sağlar [5]. Dolayısıyla, uçağa park halinde elektrik gücü sağlayan EPU'ların buna uygun güce ve uçağın ise bu gücü uygun şekilde alabilmesini sağlayacak devre yapısına sahip olması gerekir. Geniş gövdeli uçaklarda, EPU'nun güç sistemini beslemesi için kolayca erişilebilecek bir noktadan uçağa bağlanmasına olanak sağlayacak bir bağlantı noktası oluşturulmuştur (Şekil 1). Altı konnektörlü bağlantı elemanıyla EPU uçağa bağlanır. Bu altı pinden dört tanesi kalın ve uzun, iki tanesi kısa ve incedir. Bu dört uzun pin 3 faz ve bir nötr bağlantısı için, iki kısa pin ise EPU'nun geri besleme kontrolünü sağlayan 28 volt doğru akım (Direct Current, DC) bağlantısı ve EPU'nun bağlandığını gösteren lambaya enerji sağlayan bağlantı için kullanılır. Ayrıca, bu iki kısa pinle bağlantı fişinin sökülmesi ve takılması sırasında 3 faz gücün önceden kesilmesiyle ark oluşumu önlenir. Küçük uçaklar ise 28 volt DC ile çalışmaktadır (Şekil 2) [4,15].

EPU, uçağa ön iniş takımında bulunan iki adet priz aracılığıyla bağlanır. Prizler birbirinden bağımsız olarak 90 Kilo Volt Amper (KVA), $400 \mathrm{~Hz} \mathrm{115/200} \mathrm{V'luk} \mathrm{güç} \mathrm{sağlar.} \mathrm{EPU'nun} \mathrm{sistemleri} \mathrm{beslemek} \mathrm{üzere} \mathrm{kullanılmasından} \mathrm{önce,} \mathrm{uçak} \mathrm{üzerinde} \mathrm{yapılması}$ gereken bazı işlemler vardır. Bu işlemler uçakta bulunan kontrol listelerinde (check list) belirtilmiştir. Bu kontrol listesi, uçak el bakım kitapçığı olan uçak bakım kitabı (Aircraft Maintenance Manuel, AMM)'nda bulunmaktadır [4,14-15].

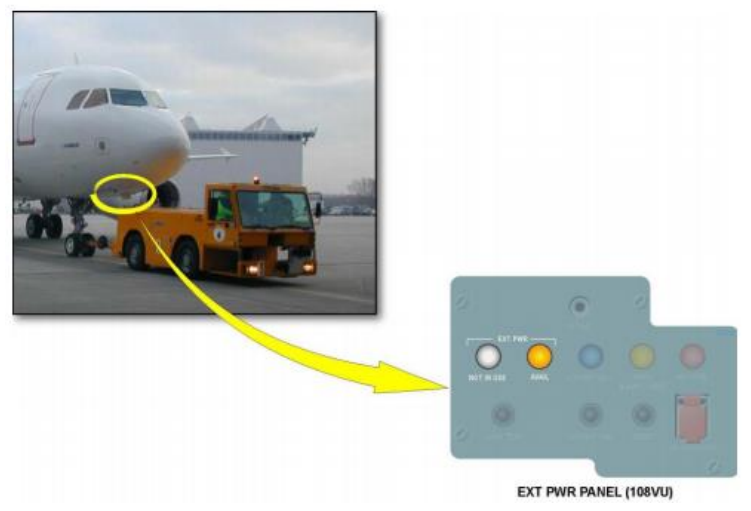

Şekil 1. EPU'nun uçağa bağlatı noktası 


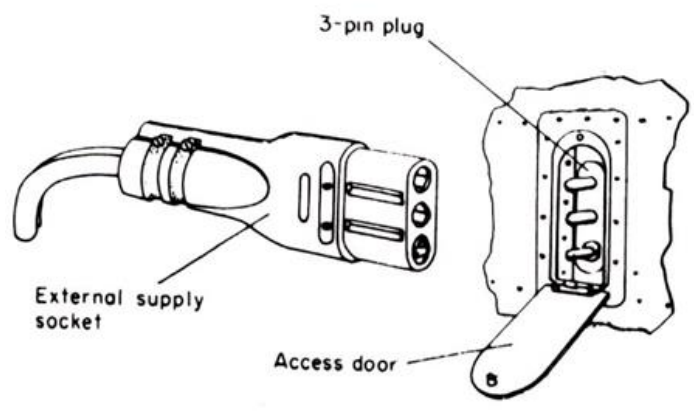

Şekil 2. EPU bağlantı noktası soketi

EPU aracılığıyla uçağa enerji verilmesinde AMM prosedürü uygulanmaktadır. Bu çalışmada açıklanan prosedür Airbus 321 uçağı için geçerli olup, hemen hemen tüm uçaklarda da benzer şekilde uygulanmaktadır. Güç kaynakları ile ilgili açıklamalar AMM bölümlerinden Chapter 24'de bulunmaktadır [4]. Kullanılan yöntem her iki giriş için de aynı prosedüre sahiptir [15].

EPU kablosu uçağa bağlandıktan sonra güç kablosunun izolasyonunun tam olmasına dikkat edilmelidir. Ayrıca 90K VA'dan daha düşük güç gerektiren sistemlerde kullandığımızda, aşırı yükleme meydana gelebileceğinden dolayı dikkatli olunmalıdır. Aşırı yüklenme sonucu uçaktaki bütün bilgisayarların resetlenmesi gerekebilir. Tüm bu uyarıların dikkate alınıp uygulanmasından sonra uçak üzerindeki prosedürler aşağıdaki gibidir [15].

Enerjilendirme Prosedürü;

- Elektronik paneldeki jeneratör (generator, GEN1), GEN2, APU GEN, BUS TIE, Alternatif Akım Ana Besleme (Alternative Current Essential Feed, AC ESS FEED) ve COMMERCIAL butonlarının basılı olması gerekmektedir. Diğerlerinin ise serbest bırakıldığından emin olunmalıdır.

- 212VU'da (fin numaralı) bulunan havalandırma kısmında, EXTRACT ve kabin fan (Cabin Fan, CAB FANS) basılı olmalıdır.

Tüm bunlar yapıldıktan sonra EXT POWER düğmesine basılarak, yerde bulunan EPU aracılığıyla uçağa elektrik verilir.

\section{SCADA}

Teknolojideki son gelişmelerden bilgisayar ve bilgisayarlarla ilgili cihazlardaki maliyet düşüşleri, uzaktan otomasyon sistemlerinin teknik ve ekonomik yönden verimli bir hale getirmiştir. Örneğin, havaalanlarındaki pist aydınlatma sistemlerinin uzaktan izlenmesi, hızlı ve etkin bir şekilde aydınlatma sistemlerinin kontrolünü sağlamaktadır. Personel ve pist güvenliği sağlanmakta, sürekli ve kaliteli elektrik enerjisi sağlanmaktadır. Sistem çalışmasında oluşan bilgilerin arşivlenmesi ve istatistik raporların değerlendirilmesi ile en etkin ve ekonomik pist aydınlatmaları sağlanmaktadır.

Kar amacıyla kurulan ticari işletmelerde amaç, en düşük maliyet ile en güvenli ve en kaliteli hizmeti sunmaktır. İşletmelerde SCADA yazılım paketleri ile yöneticiler, verileri daha kolay kontrol edebilir ve en yüksek oranda verim alınması sağlanabilir. SCADA yazılımları işletmelerde, herkesin istedikleri zaman erişebilecekleri eş zamanlı ayrıntılı bilgiye ulaşmalarını sağlar.

Havacılık sektöründe havaalanlarının ışıklandırma sistemlerinde sıklıkla tercih edilmektedir. Bir ara yüz olan SCADA, çeşitli araçlar vasıtasıyla diğer ekipmanlara ulaşmakta ve elverişli bir organizasyon haline gelerek sistemi izleme ve kontrol etmeye imkân sağlamaktadır [7,16-17]. Çok kısa mesafelerden, kilometrelerce uzaklıklardaki valf, röle, anahtar, sensör gibi ekipmanlar kontrol edilebilmektedir.

Günümüzde SCADA sistemleri, endüstriyel işlemlerde özel ve genel amaçlar için kullanılmaktadır. Birbirinden uzak sistemlerin çeşitli sensör, valf veya kontaklar ile ardışık olarak çalışması sağlanır. Birimler arası uzaklık, birkaç metreden kilometrelerce uzaklığa kadar değişsebilir. SCADA, analiz ve kontrol için gerekli bilgileri toplayarak, topladığı bilgileri karar merkezine iletir. Daha sonra, ulaşılan bilgiler karar merkezinde bulunan operatöre birçok ekran ile iletilir ve operatörün insiyatifi ile uzaktaki sistemler kontrol edilir. Operatör, bazen değerlendiren bir bilgisayar bazen de bir insan olabilir. Operatör tarafından toplanan bilgiler doğrultusunda verilen komut, röle mantığı ile gerekli birimlere iletilir. Teknolojinin gelişmesiyle, röle mantığı diğer araçlar ile birleştirilerek daha kullanışlı PLC, IED ve DCS gibi programlanabilir mantık kontrolörleri endüstride yaygın olarak kullanılmaktadır [18]. PLC'ler yaygınlaşmış ve sistemler daha akıllı hale gelirken ebatları ve ağırlıkları küçülmüştür. PLC'ler (Programmable Logic Controller) ve DCS (Dağıtımlı/Dağıtılmış kontrol sistemleri) Şekil 3'de verilmiştir. 


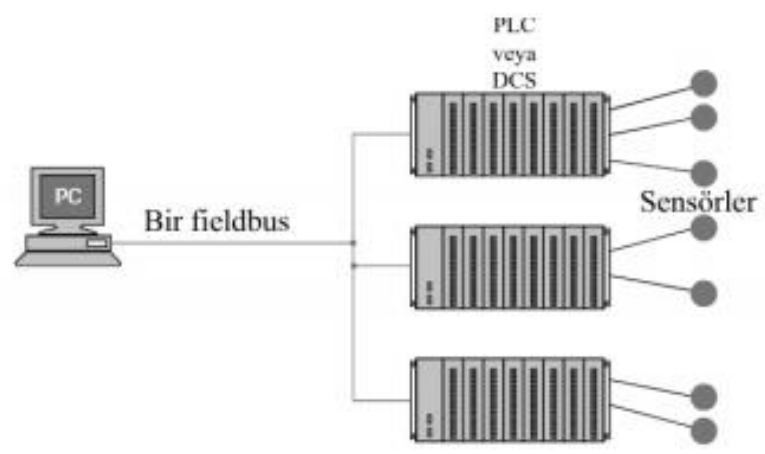

Şekil 3. Bağlantı örneği

Daha akıllı ve küçük ebatlı sistemlere ihtiyaç arttıkça, sensörler, PLC ve DCS'lerin akıllılık düzeyine göre tasarlanmaktadır. Bu aletler, IED (akıllı elektronik aletler) olarak bilinmektedir. IED'ler, profibus, devicenet ya da foundation fieldbustan PC'ye, fieldbuslar üzerine bağlanmaktadır. Bunlar; veri kazanabilecek, diğer aletlerle bağlantı kurabilecek ve tüm program içinde kendi görevlerini yerine getirebilecek akıllılıkta kapasiteye sahiptir. Bu süper akıllı sensörlerden her biri, panelde birden fazla sensöre sahip olabilir. Genel olarak bir IED; analog girdi sensörünü, analog çıktısını, PID kontrolünü, komünikasyon sistemini ve program hafizasını bir alette birleştirir (Şekil 5). Beklendiği üzere IED analog girdi sensörü, analog çıktısı, PID kontrolü, bağlantı sistemini ve program hafizasını bir alette birleştirebilir [18].

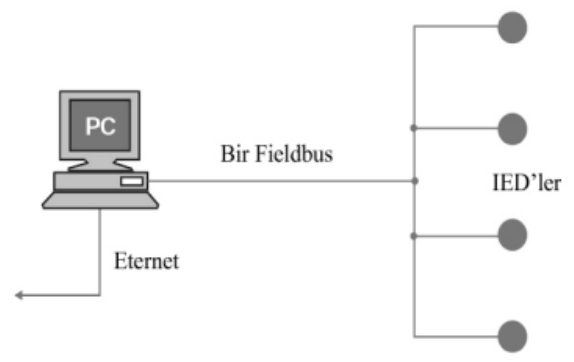

Şekil 4. PC'den IED'ye bağlantı

\section{Uçak Sistemlerinin SCADA İle Tasarım Uygulamaları}

Bu çalışmada, hava araçlarına ait Stall Uyarı Sisteminin ve Harici Güç Ünitesi SCADA ile tasarımı ele alınmıştır.

\subsection{SCADA Kontrollü Stall Uyarı Sisteminin Tasarımı}

Alternatif uyarı sistemi, yardımcı kaptan (first officer, F/O) ve Captain navigasyon göstergesi (navigation display, ND) ünitesinde birbirinden bağımsız bilgi beslemesi olarak çalışmaktadır. Gösterilen ekranda motor trust $(\mathrm{T})$ değerleri, elevator açıklık açısı ve şekilleri ile birlikte güvenilmez hava hızı (Unreliable Airspeeed) bilgileri ve otomatik pilot (AP) durum bilgisi gösterilmektedir. Uyarı sistemi uyarı (alert) durumunda sesli ve görsel olarak ikaz vererek uçuş mürettebatını uyarmaktadır. Olası bir unreliable airspeed durumunda ise farklı görsel ve sesli ikazlar verilmektedir. İki çeşit ikaz tipi bulunmaktadır. Bunlar, kabul edilebilir (acceptable), dikkat (watch out) fazlarıdır. Kabul edilebilir (acceptable) fazında AP modu uçuş mürettebatına yardımcı olmaktadır. Diğer dikkat (watch out) fazında ise AP modu de-aktif bir şekilde, kontrolü uçuş mürettebatına bırakmaktadır.

Oluşturulan alternatif sistemde, ardışık işlemlerin kontrolü Omron [CP1L] Tipi Simülasyon PLC kullanılmıştır. PLC yazılımı için kaydediciler, özel ve genel kontak ve anahtarlama elemanları, özel fonksiyonlu bloklar kullanılmıştır. Tablo 1'de "D" biti ile sayısal değerlerin gösterilmesi ve kaydedilmesi gerçekleştirilmiştir. Burada, her D bitinin hangi değerleri taşıdığı gösterilmektedir. "I" biti ile kontak ve role işlemleri gerçekleştirilmiştir. Tablo 1'de her bir I bitinin hangi anahtarlama ve role bilgisini ifade ettiği gösterilmiştir. "W" biti ise, ladder diyagramda yardımc1 role görevi görmüştür. 
European Journal of Science and Technology

Tablo 1.Stall uyası sistemi Bit bilgileri

\begin{tabular}{|c|c|c|c|c|c|}
\hline $\begin{array}{l}\text { Kaydedici } \\
\text { Bitler (D) }\end{array}$ & Açıklama & $\begin{array}{l}\text { Giriş/Çıkış } \\
\text { Bitleri (I) }\end{array}$ & Açıklama & $\begin{array}{l}\text { Yardımcı Röle } \\
\text { Bitleri }(W)\end{array}$ & Açıklama \\
\hline D0 & İrtifa & 0.00 & Uçak Elektrik On/Off & 0.00 & Motor Trust Arttırma \\
\hline D1 & IAS & 0.01 & Uçak Motor Çalıștırma & 0.01 & Motor Trust Azaltma \\
\hline D2 & CAS & 0.02 & Motor Trust Arttırma & 0.02 & İrtifa Sensör \\
\hline D3 & TAS & 0.03 & Motor Trust Azaltma & 0.03 & İrtifa Arttırma \\
\hline D4 & GS & 0.04 & 1. Batarya On/Off & 0.06 & $\begin{array}{l}\text { Yeşil Hidrolik Kesme } \\
\text { Rölesi }\end{array}$ \\
\hline D5 & $\begin{array}{l}\text { Elevator } \\
\text { Hareket Açısı }\end{array}$ & 0.05 & $\begin{array}{l}\text { Oto pilot (Auto Pilot, A/P) } \\
\text { On/Off }\end{array}$ & 0.07 & $\begin{array}{l}\text { Mavi Hidrolik Kesme } \\
\text { Rölesi }\end{array}$ \\
\hline D6 & $\begin{array}{l}\text { Sağ Motor } \\
\text { Trust }\end{array}$ & 0.06 & $\begin{array}{l}\text { Stall Warning System devre } \\
\text { kesici (Circuit Breaker, C/B) }\end{array}$ & 0.08 & İrtifa Azaltma \\
\hline D7 & $\begin{array}{l}\text { Sol Motor } \\
\text { Trust }\end{array}$ & 0.07 & 2. Batarya On/Off & & \\
\hline D10 & IAS/CAS & 0.08 & Yeşil Hidrolik Pompası & $\begin{array}{l}\text { Giriş/Çıkış } \\
\text { Bitleri (I) }\end{array}$ & Açıklama \\
\hline D11 & IAS/TAS & 0.09 & Elevator AoA Arttırma & 1.09 & $\begin{array}{l}0 \text { Derece Sensör Elevator } \\
\text { Rölesi }\end{array}$ \\
\hline D12 & IAS/GS & 0.10 & Elevator AoA Azaltma & 1.10 & İrtifa Sabit Sensör Rölesi \\
\hline D13 & CAS/IAS & 1.00 & Uçak Elektrik Rölesi & 1.11 & $\begin{array}{l}\text { Mavi Hidrolik Pompa } \\
\text { Rölesi }\end{array}$ \\
\hline D14 & CAS/TAS & 1.01 & $\begin{array}{l}\text { Uçak Motor Çalıştırma } \\
\text { Rölesi }\end{array}$ & 1.12 & $\begin{array}{l}\text { Ters Açı (Reverse) } \\
\text { Elevator Pompa Rölesi }\end{array}$ \\
\hline D16 & TAS/IAS & 1.02 & Yeşil Hidrolik Pompa Rölesi & 1.13 & $\begin{array}{l}\text { Mavi Hidrolik Pompa } \\
\text { Rölesi }\end{array}$ \\
\hline D17 & TAS/CAS & 1.03 & 1. Batarya Rölesi & 3.00 & $\begin{array}{l}\text { 1. Alarm Rölesi } \\
\text { (Unreliable Airspeed) }\end{array}$ \\
\hline D18 & TAS/GS & 1.04 & Stall Uyarı Sistem Rölesi & 3.01 & $\begin{array}{l}\text { 2. Alarm Rölesi } \\
\text { (Unreliable Airspeed) }\end{array}$ \\
\hline & & 1.05 & A/P Rölesi & 5.00 & $1 / 2$ Hiz Gösterge Sensör \\
\hline D19 & GS/IAS & 1.06 & 2. Batarya Rölesi & 5.01 & 1/4 Hız Gösterge Sensör \\
\hline D20 & GS/CAS & 1.07 & Bataryalar "On" Rölesi & & \\
\hline D21 & GS/TAS & 1.08 & $\begin{array}{l}\text { +4 Derece Sensör Elevator } \\
\text { Rölesi }\end{array}$ & & \\
\hline
\end{tabular}

Script yazılım dili, ardışık işlemlerin komut veya lojik ifadelerle çalışmasına imkan veren bir yazılım dilidir. Script yazılım dili kullanıcılarına çok geniş yelpazede komut imkanı sunmaktadır. Programları zamana ve olaya dayalı çalıştırma, nesne çağırma, alarm ve noktalar üzerindeki hareketler gibi çeşitli komutları script dili ile programda uygulatmak mümkündür[19].

$\mathrm{Bu}$ çalışmada script dili, şartlı durumlar için alarm komutunu çalıştırmak amacıyla kullanılmıştır. Unreliable Airspeed durumunda hız göstergelerindeki oransal farklara (1/2 ve 1/4) göre farklı alarm ikazları vererek uçuş mürettebatını uyarmaktadır.

$\mathrm{Bu}$ çalışmanın SCADA arayüzü Cx-Supervisor Developer uygulamasıyla hazırlanmıştır. Uygulamanın sunduğu araçlardan faydalanılarak oluşturulan arayüz ladder diyagram ile dış dünya arasındaki görselliği simüle ederek uzaktan kontrolü sağlamaktadır. Şekil 5'de oluşturulan arayüzün ladder diyagramdaki hangi biti simgelediği sarı renkte belirtilmiştir.

Hazırlanan yazılım dış dünya ile irtibatlı sensör ilişkisi olmadığı için hazırlanan yazılım ve SUS'un alternatif çözüm önerisi bir simülasyon tarzında olup, manuel olarak sensörler algılamış gibi çalışmaktadır.

İlk olarak sistemimiz normal şartlar altında (uçakta elektrik varken ve sigortası basılı olduğu zaman) motor çalışmaya başlayıp, hava aracı 400ft yükseldikten sonra aktif olmaktadır. Sistem aktif olduktan sonra motor trust değer kontrolü, Ground Speed (GS), True Air Speed (TAS), Indicated Airspeed (IAS) ve Calibrated Air Speed (CAS) değerlerini, elevator pozisyon bilgisini değerlendirerek hava aracının güvenli bir şekilde seferine devam etmesini sağlamaktadır. Aksi bir durum yaşandığı zaman, AP devreden çıkarılarak uçak, uçuş mürettebatı tarafindan kontrol edilmektedir.

SUS önerisine ek olarak, hava aracı pilotlarının çok fazla başına gelen güvenilmez hava hızı (Unreliable Airspeed) durumları geliştirilmiş ikaz sistemi de eklenmiştir. Unreliable Airspeed ikaz sistemi, uçağın GS, TAS, IAS veya CAS [20-22] arasındaki gösterge değerlerinin uygunsuz olduğunda ikaz vermektedir. İki çeşit ikaz tipi bulunmaktadır. Bunlar, kabul edilebilir (acceptable), dikkat (watch out) fazlarıdır. Kabul edilebilir (acceptable) fazında AP modu uçuş mürettebatına yardımcı olmaktadır. Dikkat (watch out) fazında ise AP devre dışı olmaktadır. 


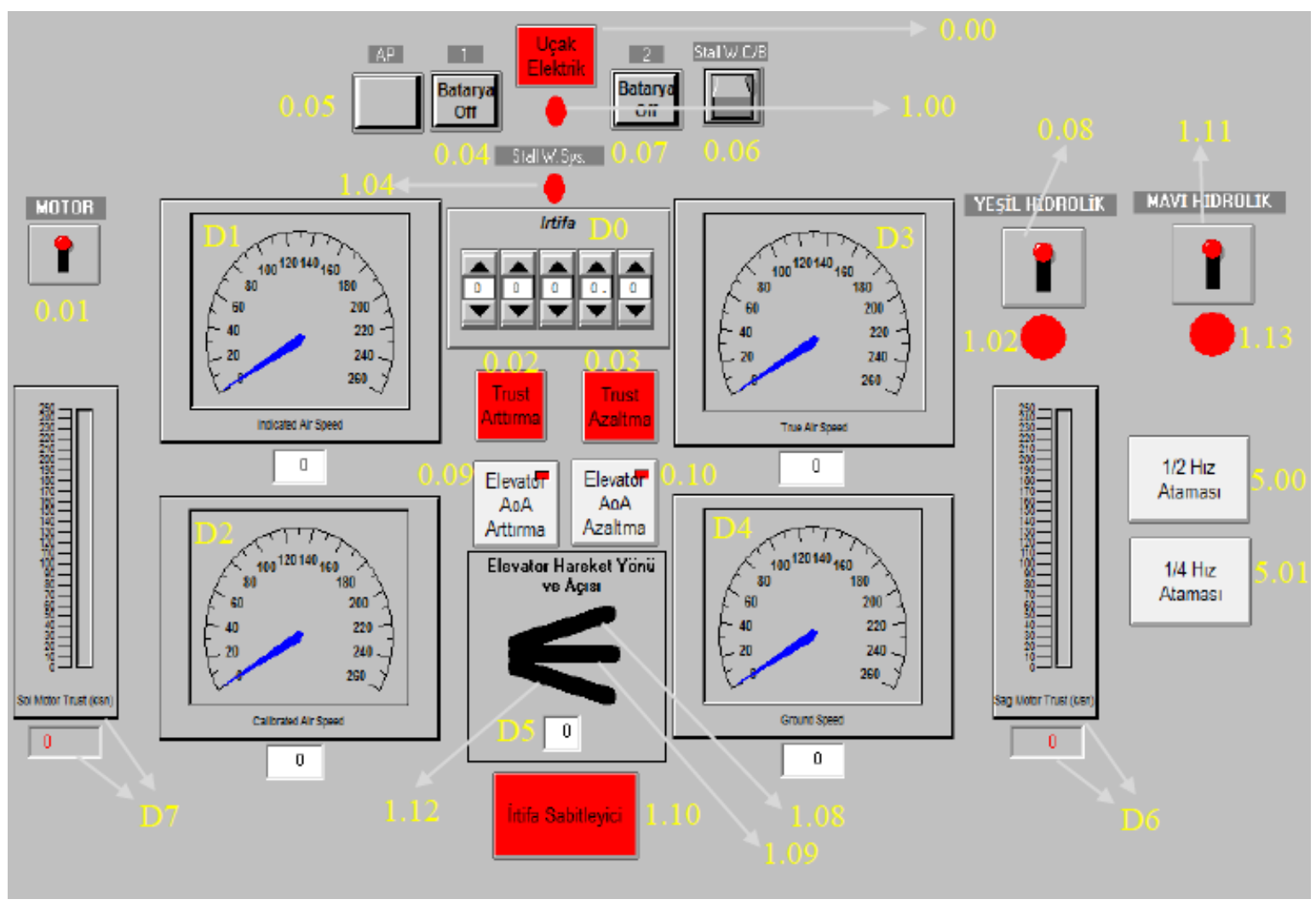

Şekil 5. Giriş çıkış bilgilerinin gösterimi

\subsection{SCADA Kontrollü Harici Güç Ünitesi Tasarımı}

$\mathrm{Bu}$ bölümde, hava araçlarının yerde bakımları esnasında, EPU kullanımına bağlı olarak meydana gelen veya gelebilecek iş kazalarından faydalanarak, EPU'ya ait farklı problemler için alternatif yöntem sunulmuştur. Sistem içerisinde ardışık sistemlerde görüntüleme ve kontrolü sağlayan SCADA çözüm yaklaşımları kullanılarak, bu yöntemin uçak bakımında etkilerinin bir teklif olarak sunulması ve uçak bakım merkezlerindeki üretilen bakım hizmetinin katma değerinin arttırılması amaçlanmıştır.

Bakım esnasında ihtiyaç duyulan elektrik enerjisini sağlamak amacıyla hava aracına yaklaştırılan EPU yine kendi üzerinde bulunan dokunmatik ekran aracılığıyla kontrol edilir. Bir adet EPU çalıştıracak buton ve acil durdurma butonu ile EPU çalışması kontrol edilmektedir. Ekran üzerinde hava aracı burun kısmına bağlanan EPU prizinin tam olarak takılı olduğunu gösteren bir lamba ve EPU tarafından üretilen güç ve frekans değerleri gösterilmektedir. Ayrıca, EPU açma ve kapama işlemi bakım esnasında istenmeyen durumlarla karşılaşmamak için son kullanıcı tarafından üretilen tek kullanımlık şifre ile EPU çalıştırılmaktadır. Ekran üzerinde iki tip mesaj bulunmaktadır. Birincisi, daimi bakım uygulamalarında hatırlatıcı uyarılar içeren mesaj tipi iken diğer mesaj tipi ise son kullanıcının hava aracında çalışan diğer teknisyenleri bilgilendirici ekran klavyesi ile girilen mesaj tipidir.

Tablo 2. Harici güç sistemi Bit listesi.

\begin{tabular}{|l|l|l|l|l|l|}
\hline $\begin{array}{l}\text { Kaydedici } \\
\text { Bitler (D) }\end{array}$ & Açıklama & $\begin{array}{l}\text { Giriş/Çıkış } \\
\text { Bitleri (I) }\end{array}$ & Açıklama & $\begin{array}{l}\text { Yardımcı Röle } \\
\text { Bitleri (W) }\end{array}$ & Açıklama \\
\hline D0 & Frekans & 0.00 & EPU On/Off & 0.00 & EPU Acil Durdurma Rölesi \\
\hline D1 & Kva & 0.01 & EPU Acil Durdurma & & \\
\hline D2 & Volt & & & & \\
\hline
\end{tabular}

Tablo 2'de ,"D” biti ile sayısal değerlerin gösterilmesi ve kaydedilmesi yapılmıştır. Burada, her D bitinin hangi değerleri taşıdı̆̆ı gösterilmektedir. "I" biti ile kontak ve röle işlemleri gerçekleştirilmiştir. Burada, her bir I bitinin hangi anahtarlama ve röle bilgisini ifade ettiği gösterilmiştir. "W" biti ladder diyagramda yardımcı röle görevi görmüştür. SCADA arayüzünde her hangi bir görevi olmayan W biti röleler, arka planda anahtarlama görevi yapmaktadır.

$\mathrm{Bu}$ çalışmanın SCADA arayüzü Cx-Supervisor Developer uygulamasıyla hazırlanmıştır. Uygulamanın sunduğu araçlardan faydalanılarak oluşturulan arayüz ladder diyagram ile dış dünya arasındaki görselliği simüle ederek uzaktan kontrolü sağlamaktadır.

Oluşturulan uygulama, toplam 2 ekrandan oluşmaktadır. EPU enerjilendiği zaman açılan ilk ekranda tarih, saat, üretilen güç, volt ve frekans değerleri, status table'da EPU durum bilgileri, EPU çalıştırma butonu, acil durdurma ve mesaj bırakma butonu açılmaktadır. Plug In Sensor bu uygulamada manuel olarak oluşturulan sensör bilgisini ifade etmektedir (Şekil 6). İkinci ekran ise, diğer kullanıcılara not bırakılan mesaj ekranıdır. Mesaj ekranına 'Leave a note' butonuna tıklanarak ulaşılır. Açılan ekranın note satırına manuel olarak not eklenerek, EPU kullanacak diğer kullanıcılara uçak üzerindeki durum hakkında bilgi verilir. ID satırına da 
manuel olarak kişi isim ve soyismi girilir. EPU'yu tekrar çalıştırmak veya kapatmak için QUIT butonuna tıklandıktan sonra üretici tarafından belirlenen kullanıcı adı ve şifre girilerek EPU üzerinde farklı bir komut verilmesi sağlanmaktadır (Şekil 7).

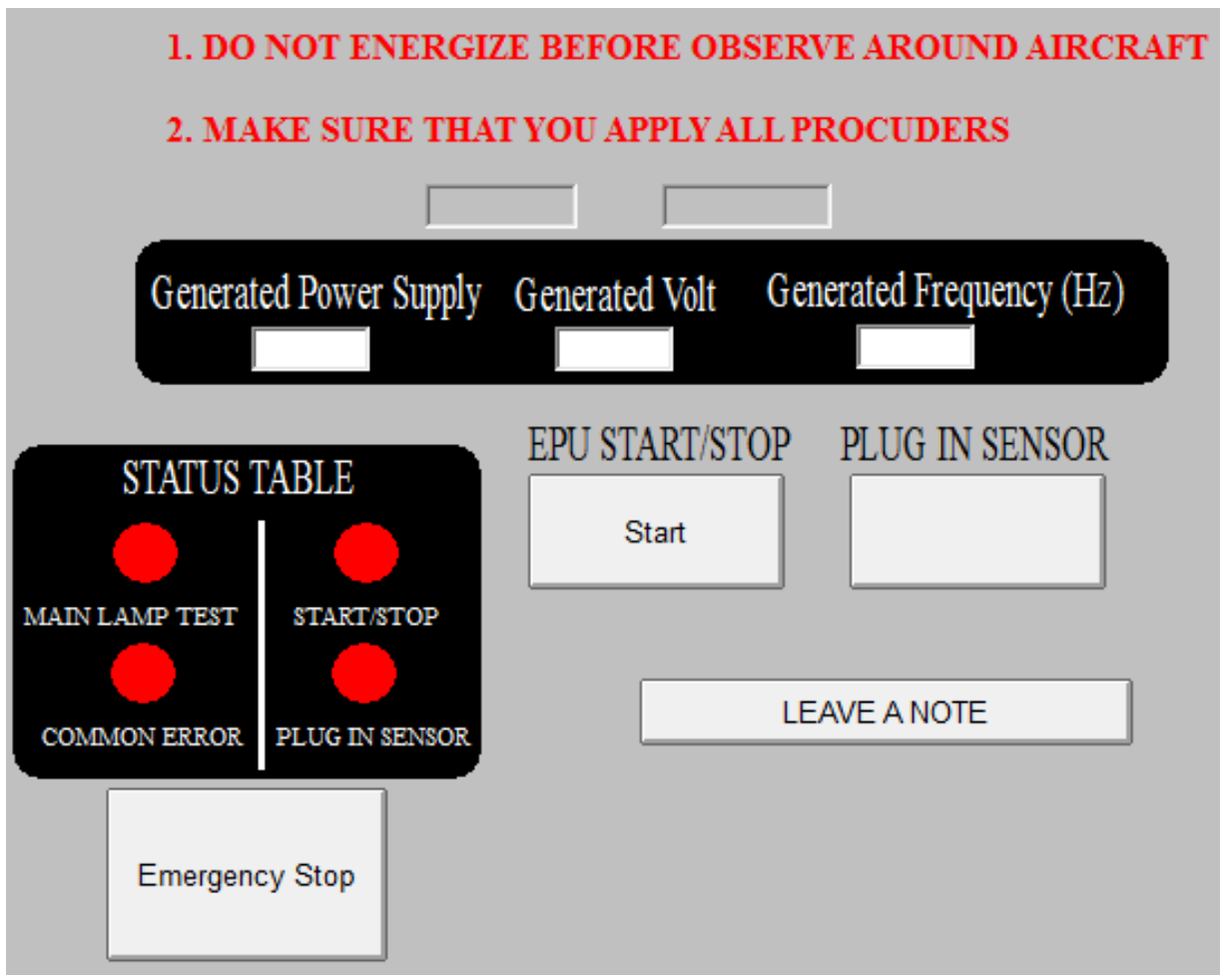

Şekil 6. EPU'nun Giriş-çıkış bilgileri

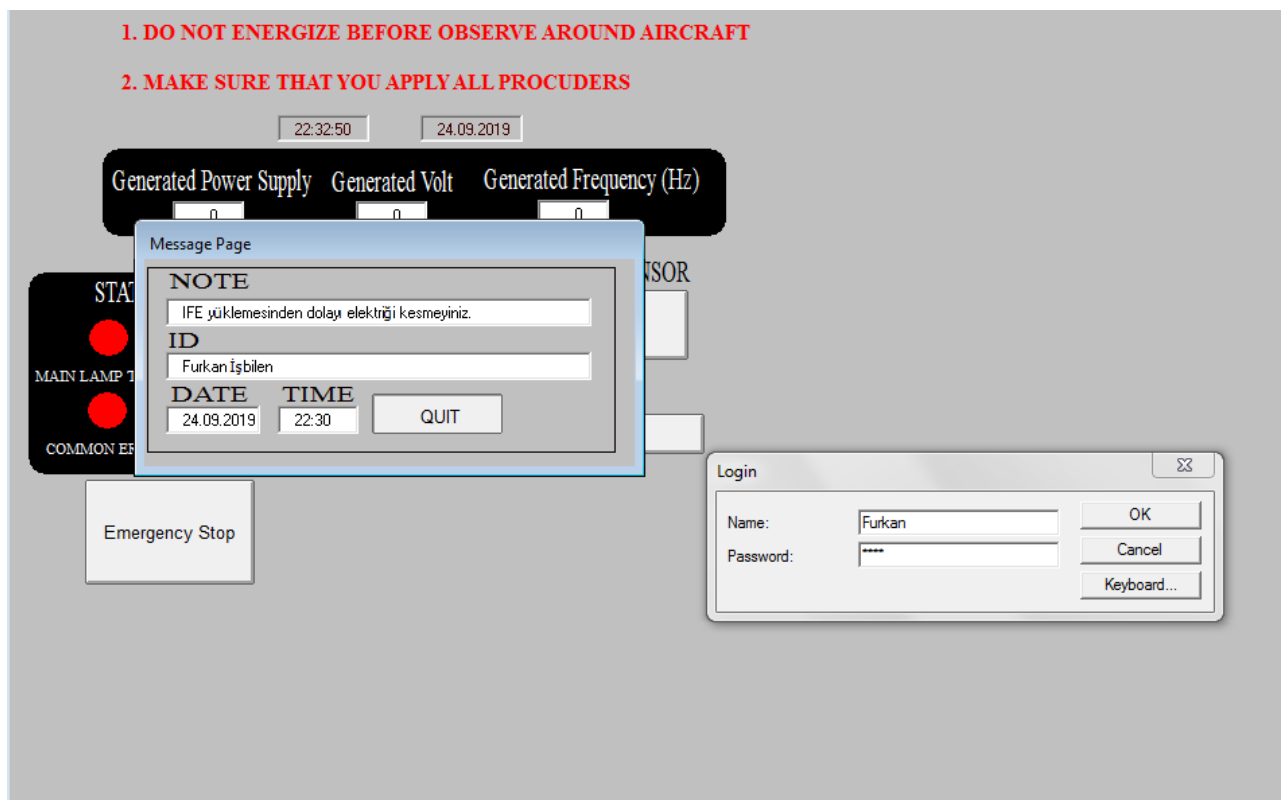

Şekil 7. Proje giriş ekranı

\section{Sonuçlar}

Hava aracının bakımı esnasında rastlanan istenmeyen can ve mal kayıpları, bakım kuruluşları için yüksek tazminatların yanında imaj kaybına da sebep olmaktadır. Bu yüzden uçak bakımında yetkili kuruluşlar için hayati öneme sahip en temel esaslardan biri iş güvenliğidir.

$\mathrm{Bu}$ çalışmada, birinci problem olarak hava araçlarının sefer esnasında stall olma durumlarına ve pilotların sıklıkla karşılaştığı unreliable airspeed durumunu önleyici çözümler üzerinde durulmuştur. Pilotlarla yapılan mülakatlar sonucu unreliable airspeed durumunun erken teşhisi ve doğru ikaz yöntemi ile meydana gelebilecek uçak kazalarının önüne geçebileceği sonucuna varılmıştır. 
Problemin çözümü amacıyla, görsel arayüz olan SCADA sistemi kullanılarak dijitalleşen kokpitlerin görsel açıdan uçuş mürettebatına daha iyi ikaz verici alternatif bir sistem sunulmuştur.

İkinci problem olarak ele alınan bakım uygulamalarında meydana gelebilecek istenmeyen elektrik kesintileri veya istenmediği halde uçağa elektrik verilmesi durumunda karşlaşılacak olumsuz sonuçların üzerinde durulmuştur. Bakım esnasında uçaktan elektrik kesildiği zaman bazı bakım operasyonlarının durduğu ve buna bağlı olarak zaman ve adam saat ücret kaybının yaşandı̆̆ı görülmüştür. Bir diğer yandan, uçak üzerinde yüksek voltaj alanlarında çalışan kişilerin, uçağa habersiz elektrik verildiğinde olumsuz elektrik çarpılmalarına maruz kaldıkları görülmüştür.

Yapılan çalışmalarda elde edilen sonuçlara göre, uçakların stalla uğradıklarında veya unreliable airspeed durumlarında uçuş mürettebatını mevcut sistemlerden daha iyi bir şekilde uyardığı açıkça ortaya konulmuştur. İkinci problemin çözümü için geliştirilen EPU kullanım ekranı sayesinde EPU enerji verilmesi veya kesilmesi şifreleme yöntemi ile olduğu için mevcut durumdan daha tedbirli bir hal aldığı söylenebilir.

\section{Kaynaklar}

[1] M. Konar, F. Işbilen, (2018) Uçaklarin External Power Unitesinin Scada İle Entegrasyonu, II. Uluslararası Multidisipliner Çalışmaları Kongresi, Adana, Turkey, pp.1-5,

[2] Konar, M., Işbilen, F., (2018). Hava Araçlarinda SCADA Kontrollü Stall Uyarı Sistemini Tasarımı. II. Uluslararası Multidisipliner Çalışmaları Kongresi, Adana, Turkey

[3] Hull, D.G., 2007. Fundamentals of Airplanes Mechanics, Springer, Berlin.

[4] TTS Integrated Training System, 2011. Module 13 Aircraft Aerodynamics, Structures and Systems for EASA part- 66. Licence Category A, B 1 and B 2.

[5] JP AVIONICS, (2009). External Power Unit for General Aviation Aircraft. (http://www.jp-avionics.com/downloads/JPAvionics\%20-\%20EPU\%20user.pdf), (Erişim Tarihi: Ocak 2020)

[6] Zalovcik, J., (1952). Summary of Stall-Warning Devices, Natinal Advisory Committee for Aeronautics, Technical Note 2676

[7] Harima, K., (2000). The Introductory course of Sequence Control Learning Guide, Japonya, JICA Publications.

[8] Skybrary, (2017).Stall Warning Systems. (https://www.skybrary.aero/index.php/Stall_Warning_Systems), (Erişim Tarihi: Kasım 2019).

[9] Etkin, B., (1972). Dynamics of Atmospheric Flight, Wiley, New York, 201-211s.

[10] NASA, (1994). Development and Certification of A New Stall Warning And Avoidance System. (: https://ntrs.nasa.gov/archive/nasa/casi.ntrs.nasa.gov/19850006198.pdf), (Erişim Tarihi: Ocak 2020).

[11] NASA, (1952). Stall Warning Devices. (https://ntrs.nasa.gov/archive/nasa/casi.ntrs.nasa.gov/19930083830.pdf) , (Erişim Tarihi: Ocak 2020)

[12] Temel, R., (2014). Hücum Açısı (http://sirramazantemel.blogspot.com/2014/10/hucum-acisi.html), (Erişim tarihi: Ocak 2020)

[13] Gracey, W., (1958). Summury of Methods of Measuring Angle of Attacks on Aircraft, NASA Technical Reports, (NACA-TN4351)

[14] Bruce, R., (2004). Aircraft Maintenance. SAE International, United State, 166 pp.

[15] Airbus, (2005). Aircraft Maintenance Manuel Chapter 24, Airbus S.A.S,Blagnac,

[16] Jeff, D., (2005). Supervisory Control and Data Acquisition (SCADA) Introduction.USA: Pacific Northwest National Laboratory Grainger Lecture Series for the University of Illinois at Urbana-Champaign.

[17] Stuart, A., (2009). The Instrumentation, Systems, and Automation Society; 4th edition. USA: International Society of Automation

[18] Rajesh, M., Vikrant, V., (2016). PLCs \& SCADA Theory and Practice.New Delhi: Laxmi Publications Pvt. Ltd.

[19] İşbilen, F., (2019). PLC Ladder ve Scada Yazılımı. (https://gofile.io/?c=zeHYRq). (Erişim Tarihi: Ocak 2020).

[20] Konar, M., \& Bağiş, A. (2016, May). Simultaneous computation of the speed and fuel parameters of flight control system by using Anfis and artificial neural networks. In 2016 24th Signal Processing and Communication Application Conference (SIU) (pp. 1389-1392). IEEE.

[21] Bagis, A., \& Konar, M. (2018). ABC and De algorithms based fuzzy modeling of flight data for speed and fuel computation. International Journal of Computational Intelligence Systems, 11(1), 790-802.

[22] Konar, M., \& Bagis, A. (2009, April). Determination of the speed parameter of flight control system by using adaptif network based fuzzy inference system. In 2009 IEEE 17th Signal Processing and Communications Applications Conference (pp. $993-$ 996). IEEE. 